\title{
High-Current Tests on High-Tension Switchgear
}

\author{
BY PHILIP TORCHIO
}

Chief Electrical Engineer, New York Edison Co.

\begin{abstract}
The article describes a series of tests on oil circuit breakers and disconnecting switches to determine their strength at brush contacts and supports in withstanding the mechanical stresses engendered by the magnetic flux due to the ,tow of large currents of the order of 100,000 amperes, as may exist at times of short circuits on large systems. Other tests were made on current transformers and potential transformer fuses.

For the first time, a synchronized motion picture machine and an oscillograph, were coupled to reproduce the coincident actions of the apparatus tested, and the variations of voltage and current in the circuit. The tests proved that practically all the circuit breakers then on the market had the brush contact placed in the wrong position, creating arcing before the operating mechanism had sufficient time to perform its function. The tests emphasized the importance of strong locks for disconnecting switches. Only single-turn primary-type current transformers and potential transformer fuses with resistance in series, were found adequate to give the service requirements.
\end{abstract}

$\mathrm{T}$

HE high-current tests on oil circuit breakers, disconnecting switches, current transformers, and potential transformer fuses were carried out in 1918 and 1919 by the engineers and the Photographic Bureau of The New York Edison Company. The manufacturing companies lent effective cooperation in arranging the apparatus for the test, and in analyzing the results. For the first time, a synchronized motion picture machine and an oscillograph were coupled to reproduce the coincident actions of the apparatus tested and the variations of voltage and current in the circuit.

\section{Oil Circuit Breakers}

In connection with the study of very high-current electric welding apparatus, certain phenomena took place on the ordinary type of brush contacts, which prompted an investigation and subsequent tests to determine what would happen on the circuit breakers used in our central stations when subjected to currents of the order of 100,000 amperes, as may exist at times of short circuits on large systems.

The phenomenon which was noted was the wellknown fact that when current is flowing in a closed circuit, the magnetic field set up by the current will tend to expand the loop outward. Therefore, if a circuit breaker is designed with a loop circuit so arranged that the mechanical pull due to the magnetic flux is to open the contact, the switch will present a weakness at that point; while if the movable contact parts are inverted so that the mechanical pull due to the magnetic flux is to force them more solidly against the fixed parts, the contact will be improved.

The circuit breakers tested were the $K-52, H-3$ and $H-6$ of the General Electric Company; and the $E-9$ and $0-1$ of the Westinghouse Electric \& Manufacturing Company.

The tests proved that practically all the circuit breakers then on the market had the brush contact placed in the wrong position, so that when the current flowed the resultant mechanical force acted in a direction opposed to the brush pressure, thus tending to open the contact at this point; whereas, if the position of the contact brushes had been reversed, the mechani-

To be presented at the 9th Midwinter Convention of the A.I.E. E., February 16-18, 1921. cal force due to this current would have been exerted in the same direction as the brush pressure, thereby tending to improve the contact.

In addition to the force exerted at the contacts, it

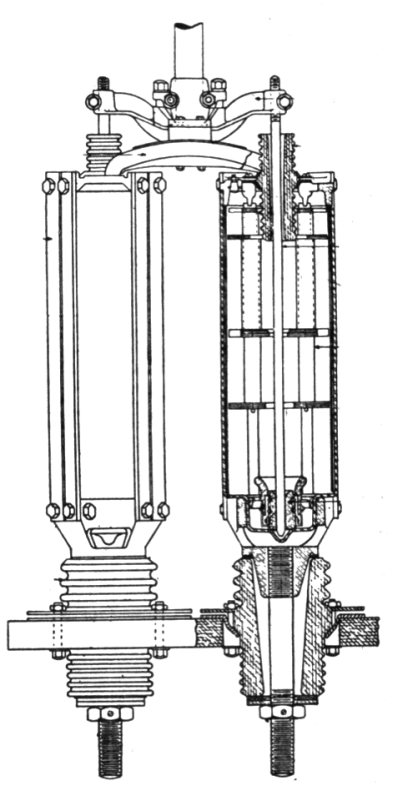

$1-\mathrm{A}$

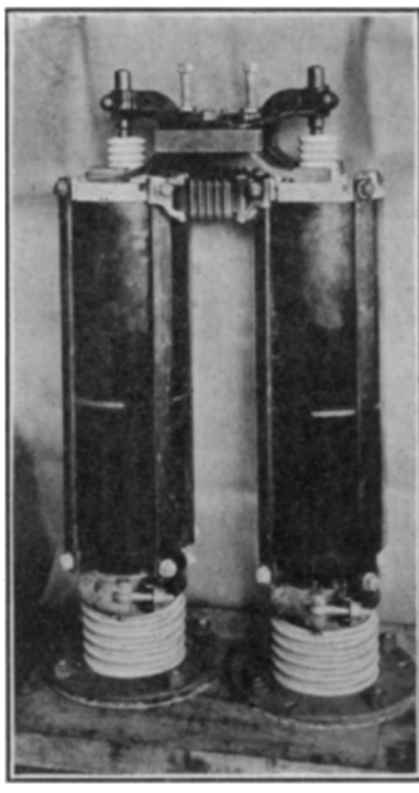

$1-\mathrm{C}$

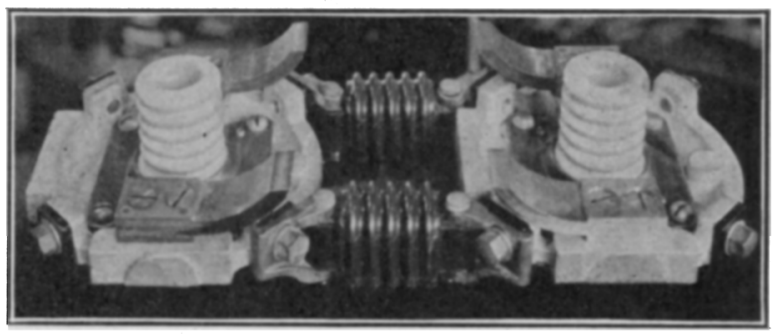

$1-\mathrm{B}$

Fig. 1-G. E. Co. Type F H-3 Oil Circuit Breaker Showing IMPROVEMENTS

1-A. Original standard construction of contacts.

1-B. Detail of new inverted contact brushes and tie insulators.

1-C. Assembly of new inverted contacts and tie insulators.

was found that the repelling force between contact supports was of such magnitude as to distort, and in some cases permanently displace, these parts.

In all these tests, the circuit breakers were locked in the closed position. The arcing, therefore, was caused by the opening of the main and arcing contacts due to 


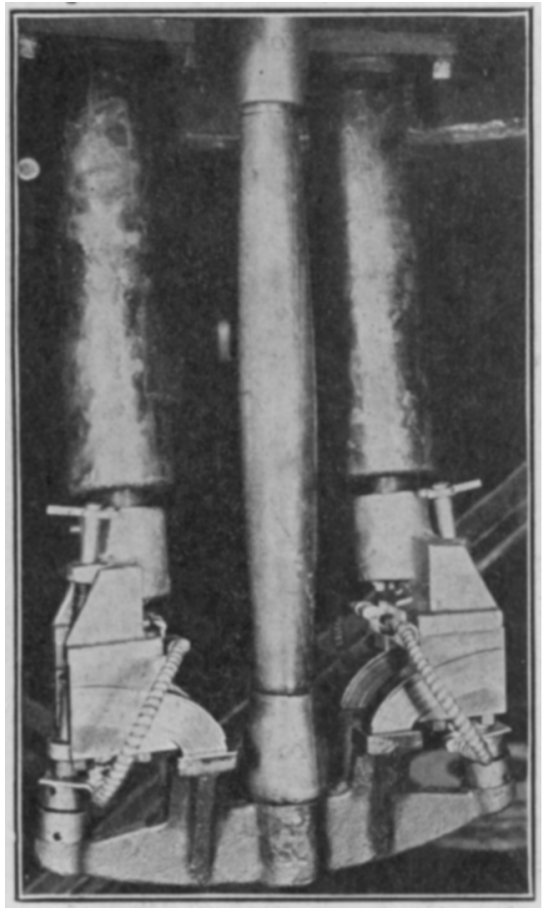

$2-\mathrm{A}$

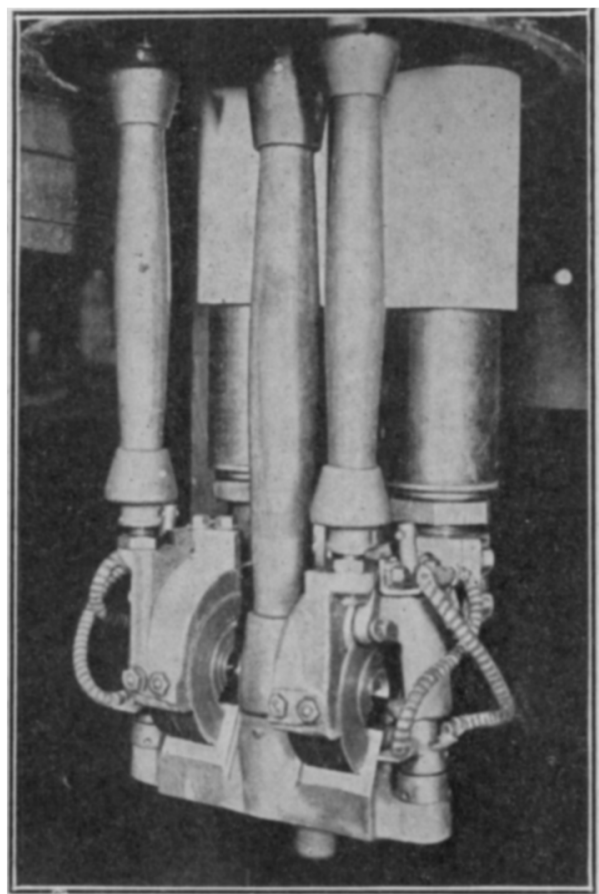

2-B

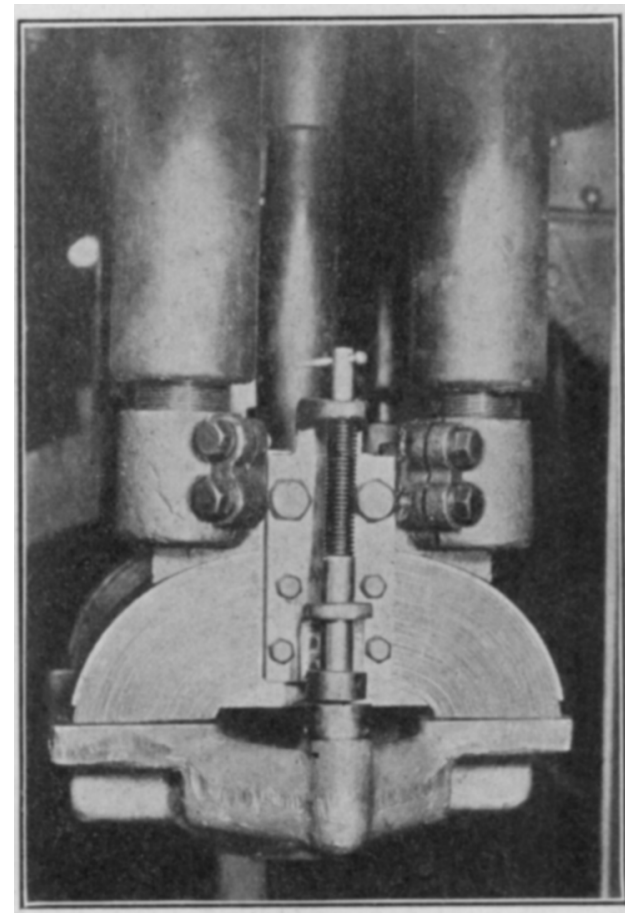

$2-\mathrm{C}$

Fig. 2-Westinghouse Elec. \& Mfg. Co. Oil Circuit Breaker Parts Showing Improvements. (Former Design Shown IN Figs. 9, 10, 14 ANd 15.)

2A. Quarter elliptic form of inverted brush contact used in the CO-2 1200-ampere, 60-cycle circuit breaker.

2-B. A circular form of inverted brush contact used in the CO-1 1200-ampere, 60-cycle circuit breakers. Considerable attractive force is obtained between the two sides of the brush and the parallel contacts carrying current flowing in the same direction.

2-C. Half elliptic form of inverted brush contact used in the 0-2, 4000-ampere, 60-cycle circuit breakers.

2-D. A new form of contact is to be used in the 0-4,3000-ampere, 60-cycle circuit breaker. There are no joints in the electrical circuit except at the contact faces and thermal losses are therefore a minimum. On short circuit, the two halves of the brush attract each other due to carrying current in the same direction and are, therefore, pressed more securely against the main contact.
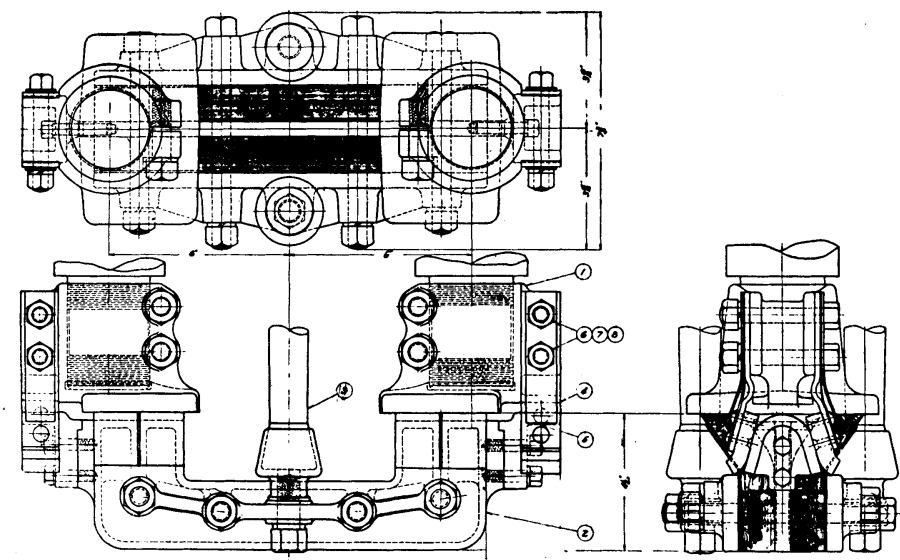

$2-\mathrm{D}$

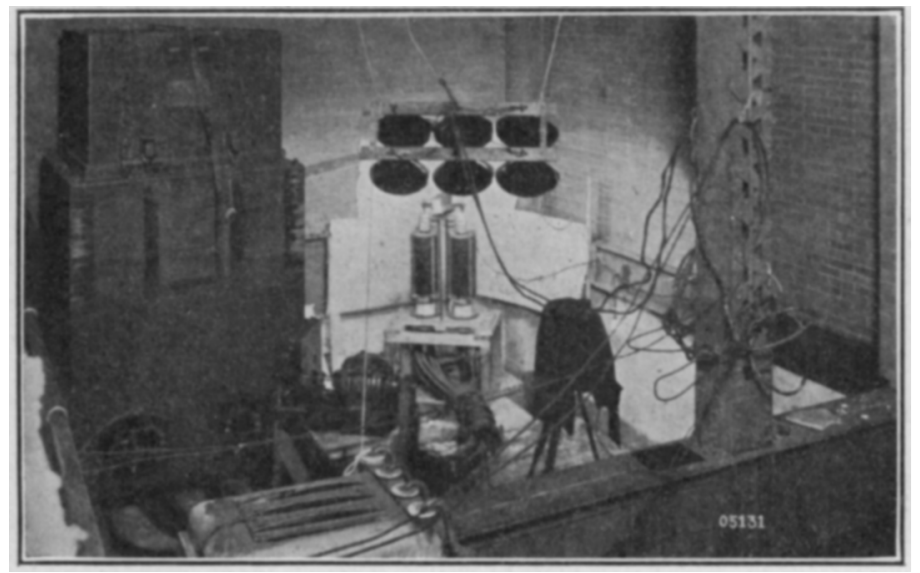

Fig. 4-Set-up of Apparatus for Tests

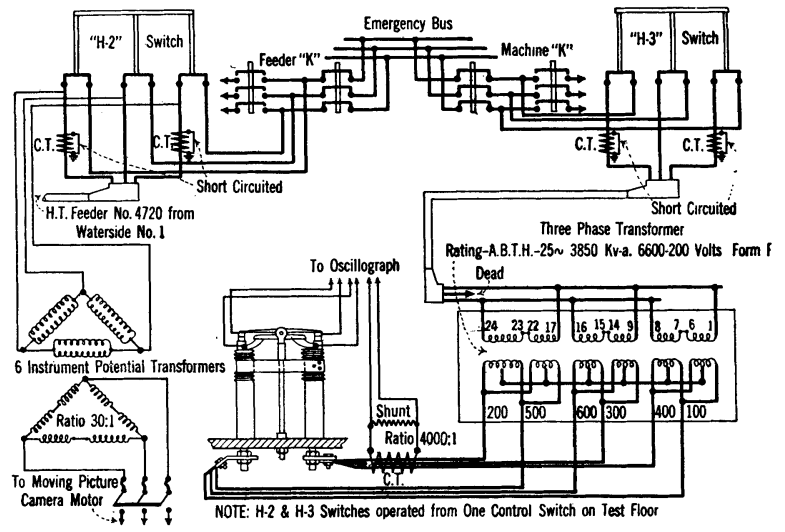

Fig. 3-Diagram of Connections for Tests

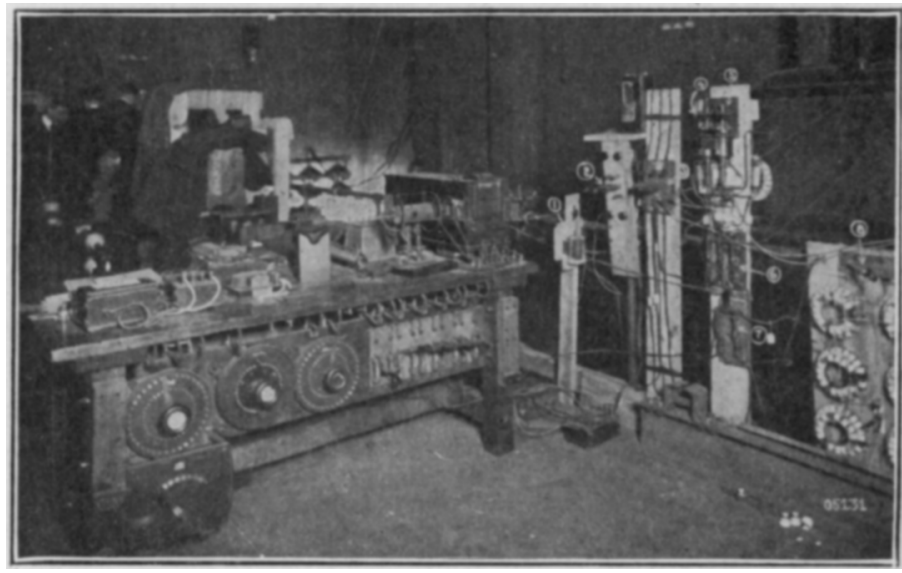

Fig. 5-Control Apparatus for Tests; Mounted on Gallery Above the Test Floor 

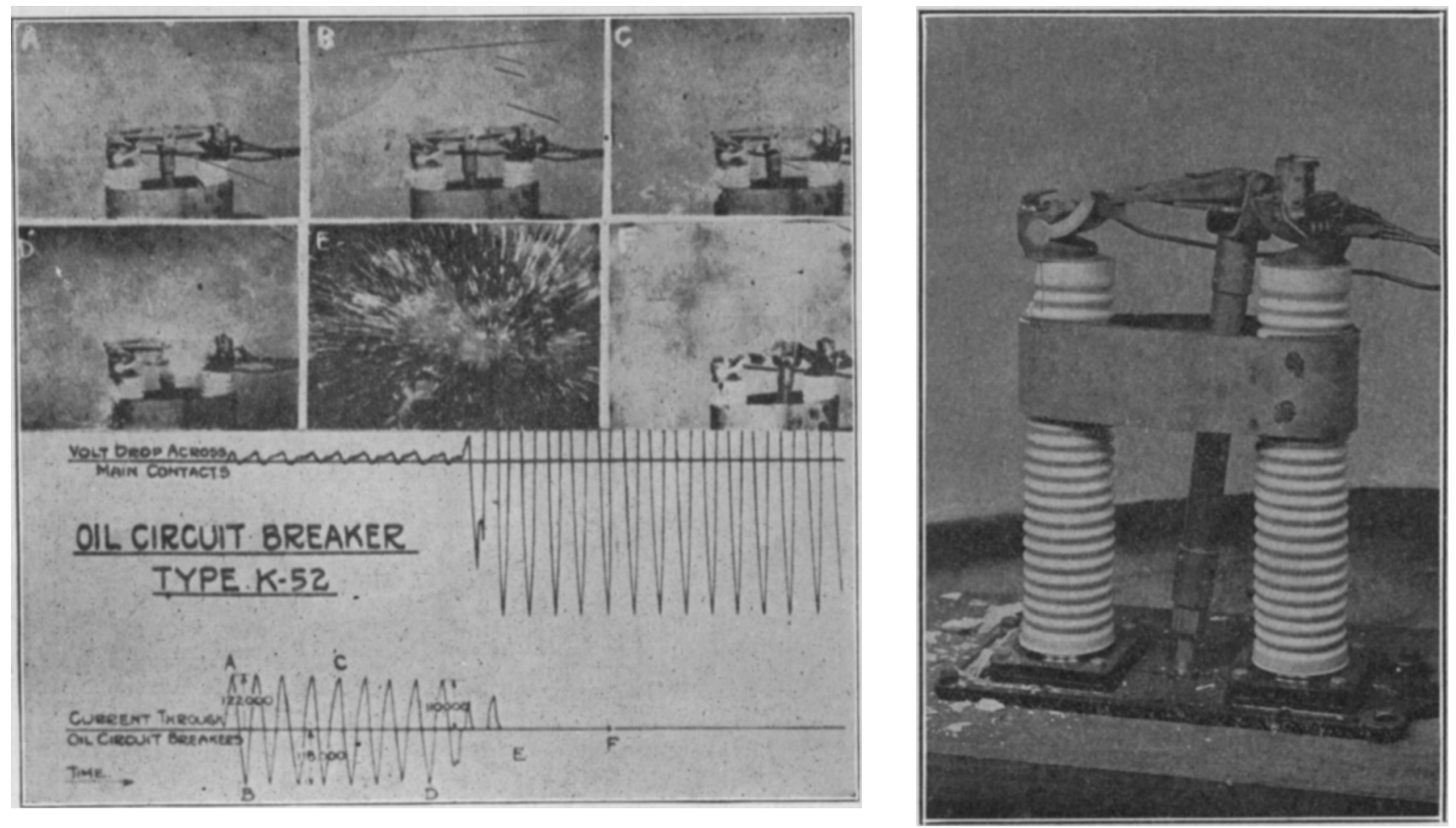

Fig. 6-G. E. Co. K-52 Circuit Breaker Reinforced With Fiber Band

Rating, $125,000 \mathrm{kv}$-a., 31,500 amperes at 2300 volts.

This circuit breaker was flrst tested at 27,000 and at 31,000 amperes mean effective which it withstood satisfactorily. It was then given 85,000 amperes mean effective which spread the porcelain pillars, breaking one at the special support, and twisted the movable contact around and entirely off the stationary contacts. Open-circuited at the 9th cycle.
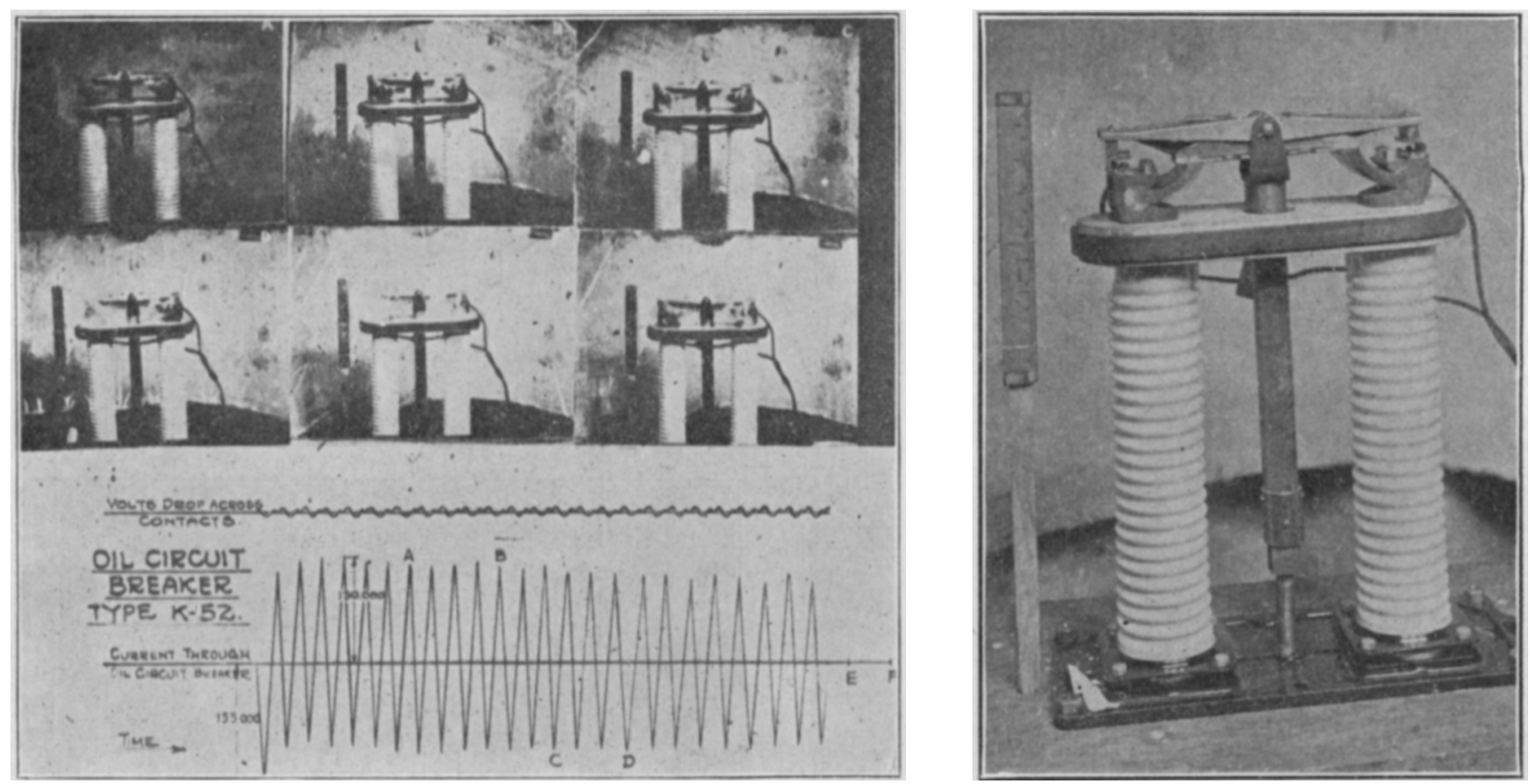

Fig. 7-G. F. Co. K-52 Circuit Breaker Reinforced With Wood and Steel

Rating 125,000 kv-a., 31,500 amperes at 2300 volts.

First withstood a test of 67,000 amperes mean effective. On 98,000 amperes mean effective the porcelain broke at 12 th cycle. Slight arcing. Total spread of contacts approximately $3 / 16$ in. 

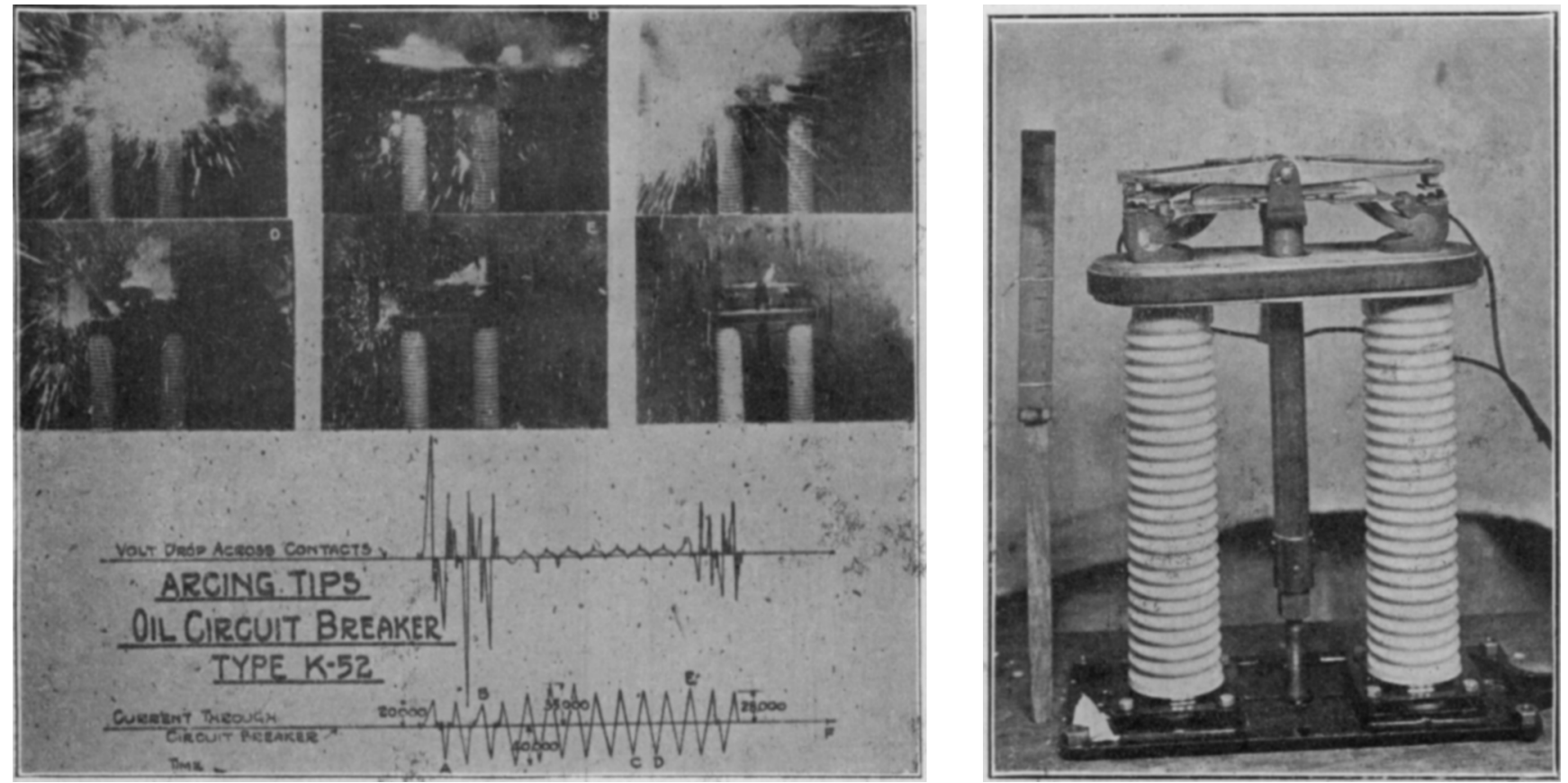

Fig. 8-G. E. Co. K-52 Crrcuit Breaker

Tets on arcing tips only. Tested at 21.000 amperes mean effective. Contacts lifted on first $1 / 2$ cycle, and for three consecutive cycles. Remained closed for seven cycles. and again opened for three cycles. Severe burning.
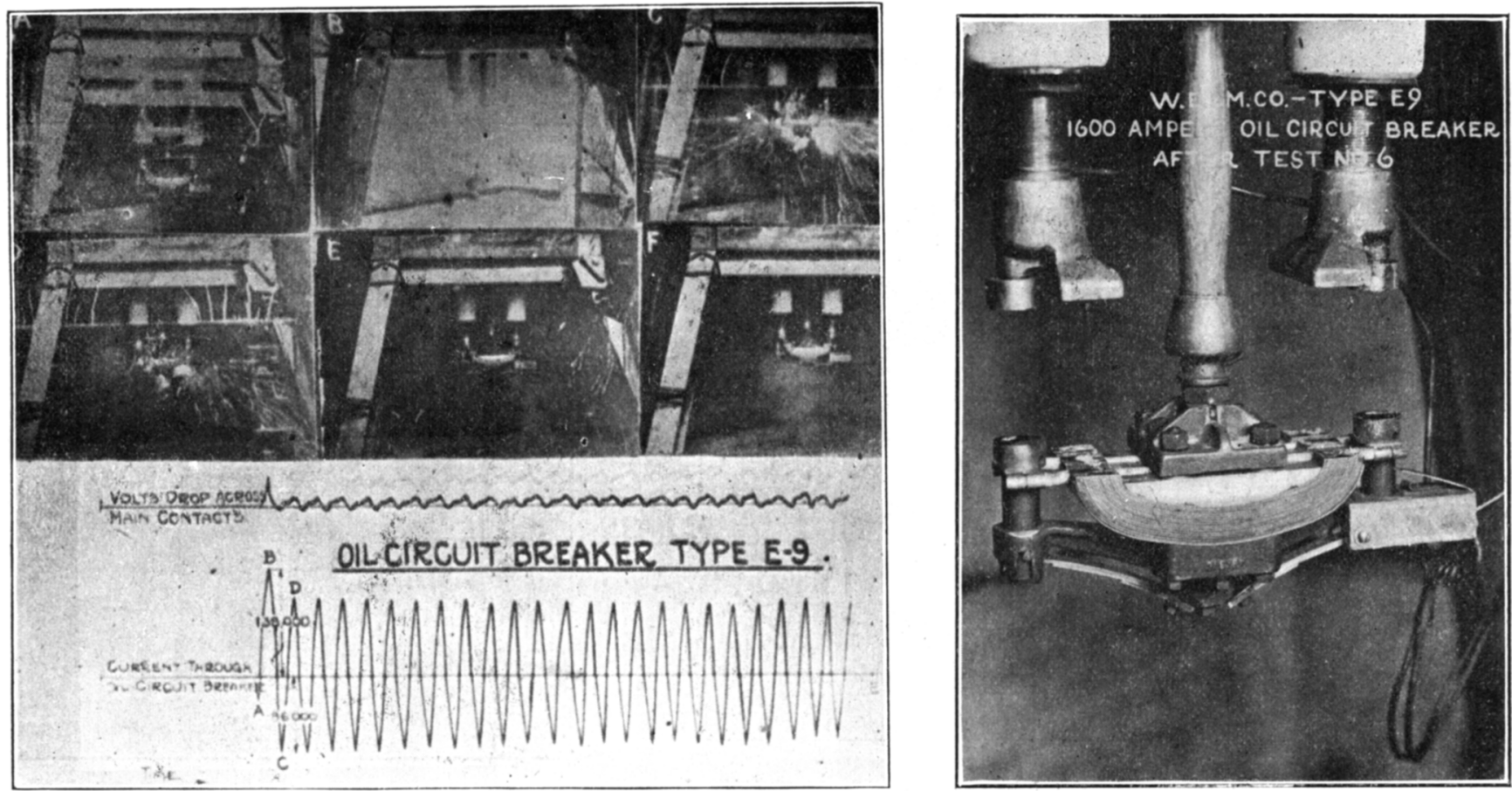

Fig. 9-Westinghouse E-9 Circuit Breaker

Rating $160,000 \mathrm{kv}-\mathrm{a} ., 40,000$ amperes at 2300 volts.

Tested at 79,000 amperes mean effective. Brushes lifted on flrst $1 / 2$ cycle, arced and froze. Total spreading of contacts approximately $5 / 32$ in. 

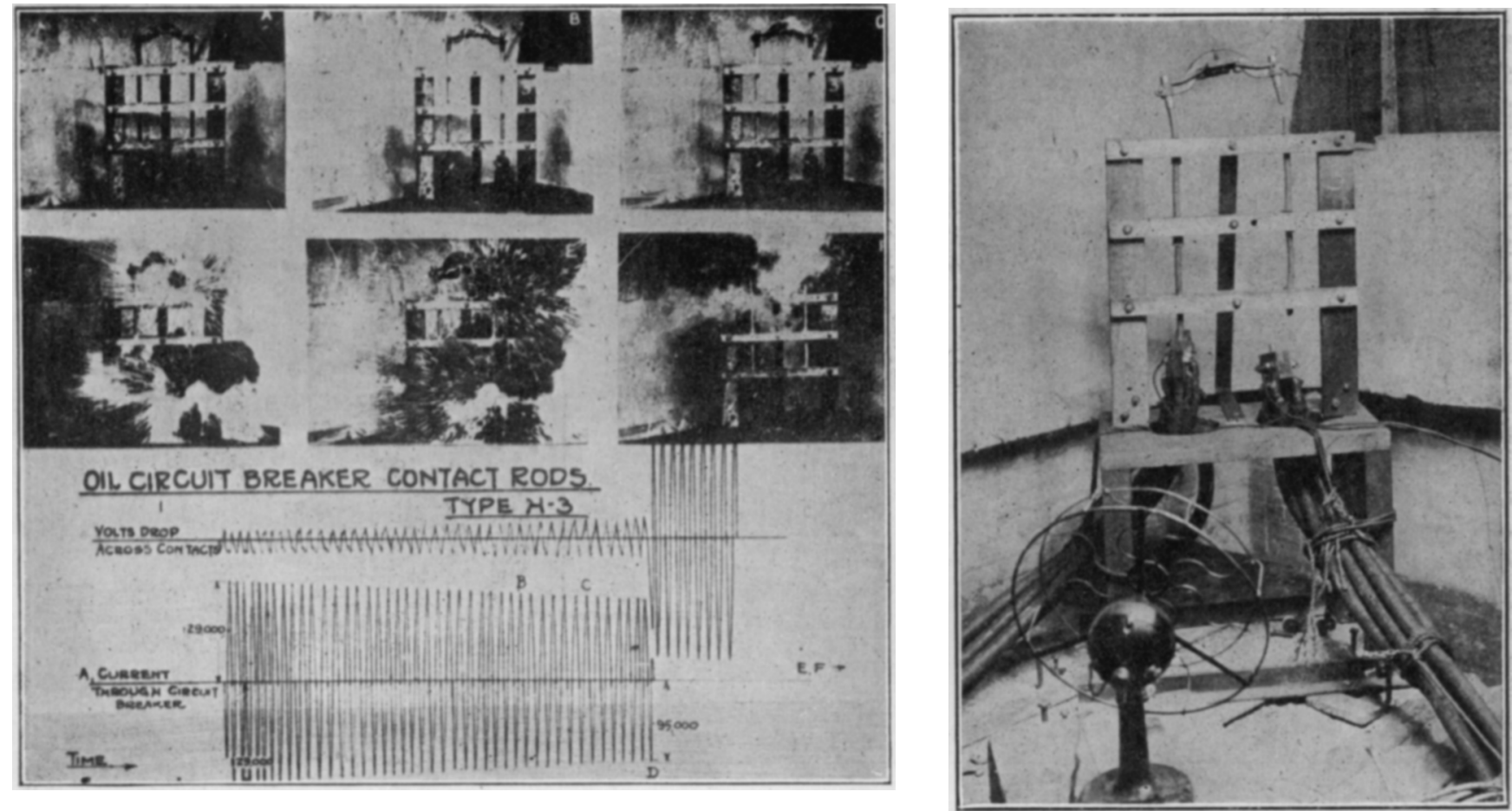

Fig. 10-Westinghouse E-9 Circuit Breaker

Rating $160,000 \mathrm{kv}-\mathrm{a} ., 40,000$ amperes at 2300 volts.

Tested at 89,000 amperes mean effective. Brushes lifted on first $1 / 2$ cycle and burned clear at $81 / 2$ cycles.
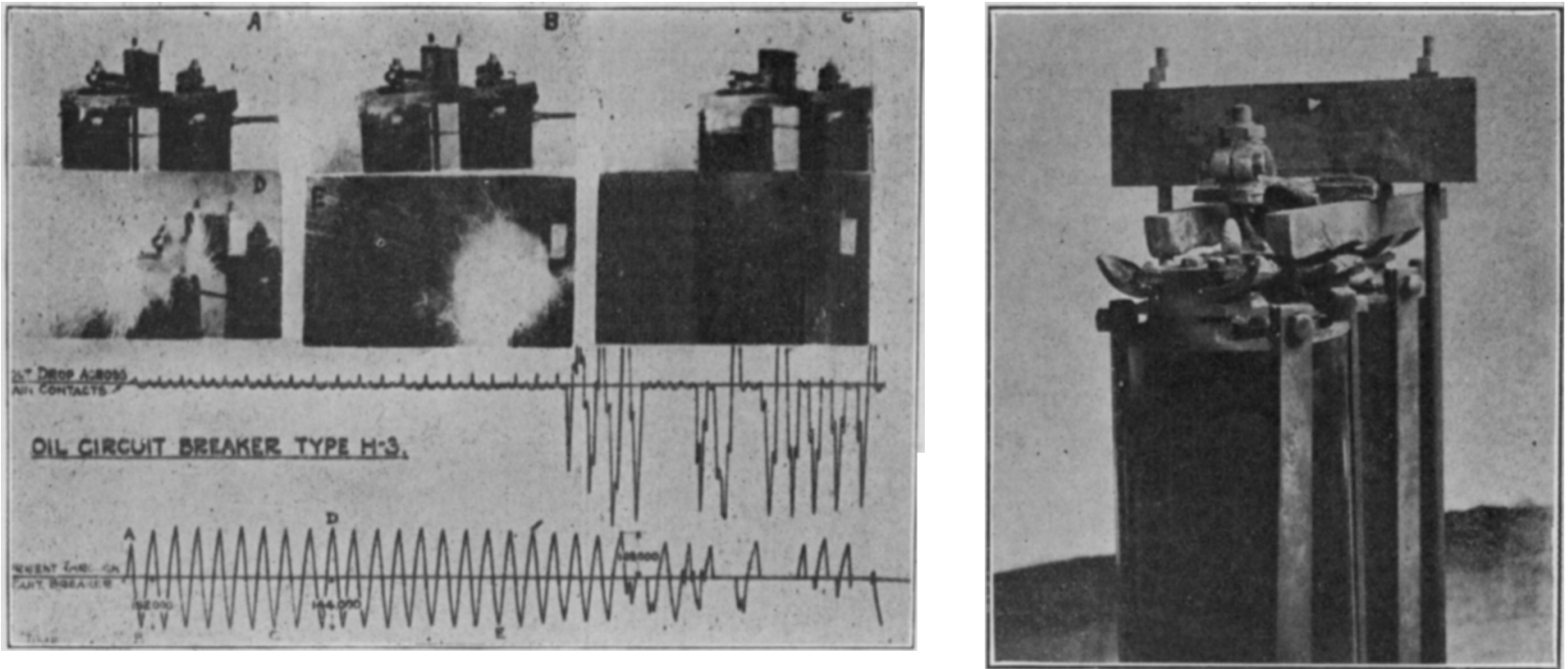

Fig. 11-G. E. Co. H-3 With Inverted Brushes

Rating $225,000 \mathrm{kv}-\mathrm{a} ., 63,000$ amperes at 2300 volts.

Tested at 103,000 amperes mean effective. Slight arcing at contacts due to vibration and spreading of pots, contact plates collapsed, one of the brass rods burned off, and switch open-circuited. 

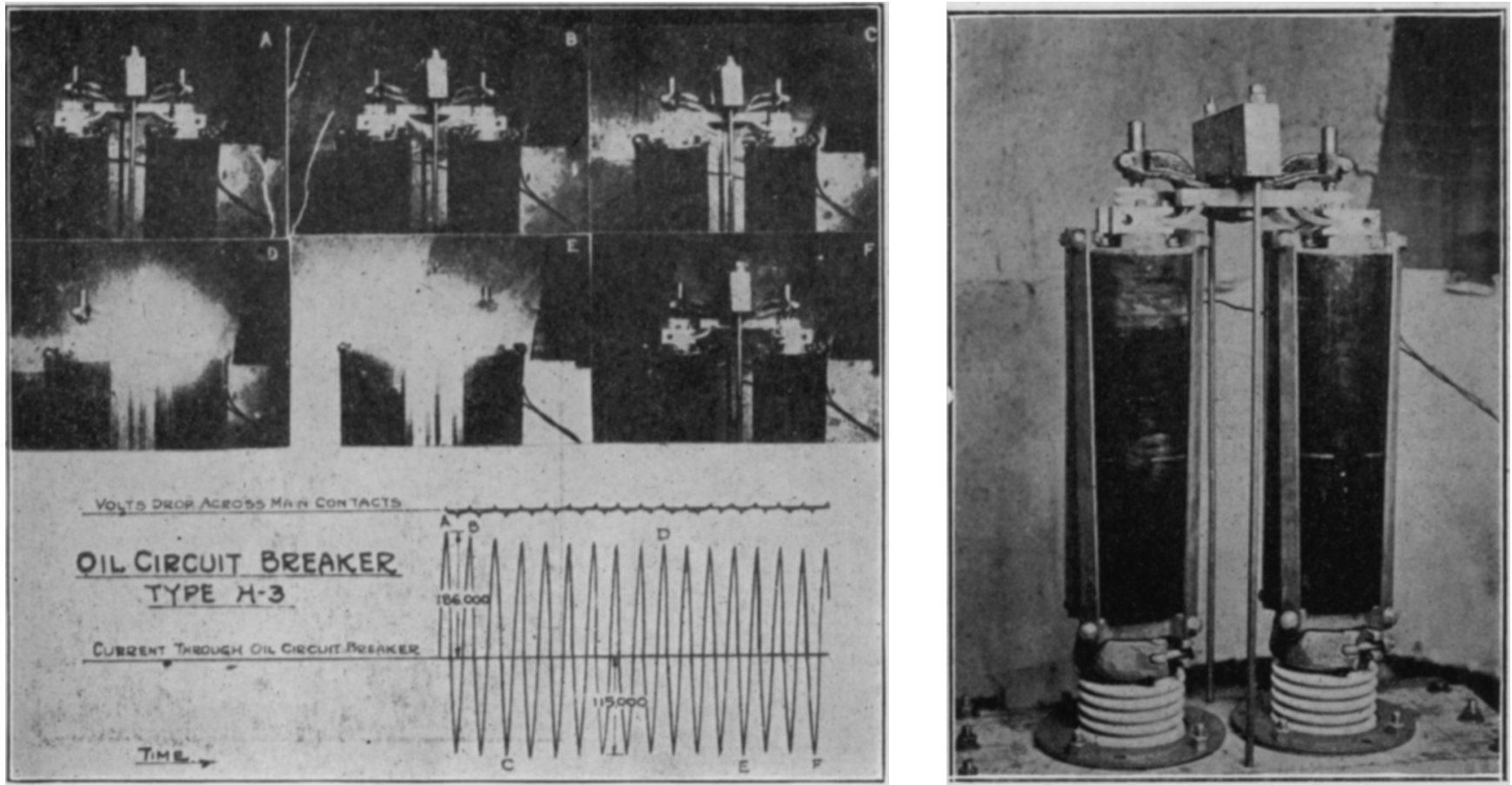

Fig. 12-G. E. Co. H-3 With Trial Brushes

Rating $225,000 \mathrm{kv}-\mathrm{a} ., 63,000$ amperes at 2300 volts

Tested at 112,000 amperes mean effective. Slight arcing at contacts due to vibration. One brass rod was bent. Total spreading of pots $11 / 8$ in. The bright irregular lines at the left edge of Section $B$ of the fllm are caused by static discharge due to the high speed at which the films were taken This appears in a number of the motion pictures, notably Section $\mathrm{E}$ of the fllm in Fig. 17.
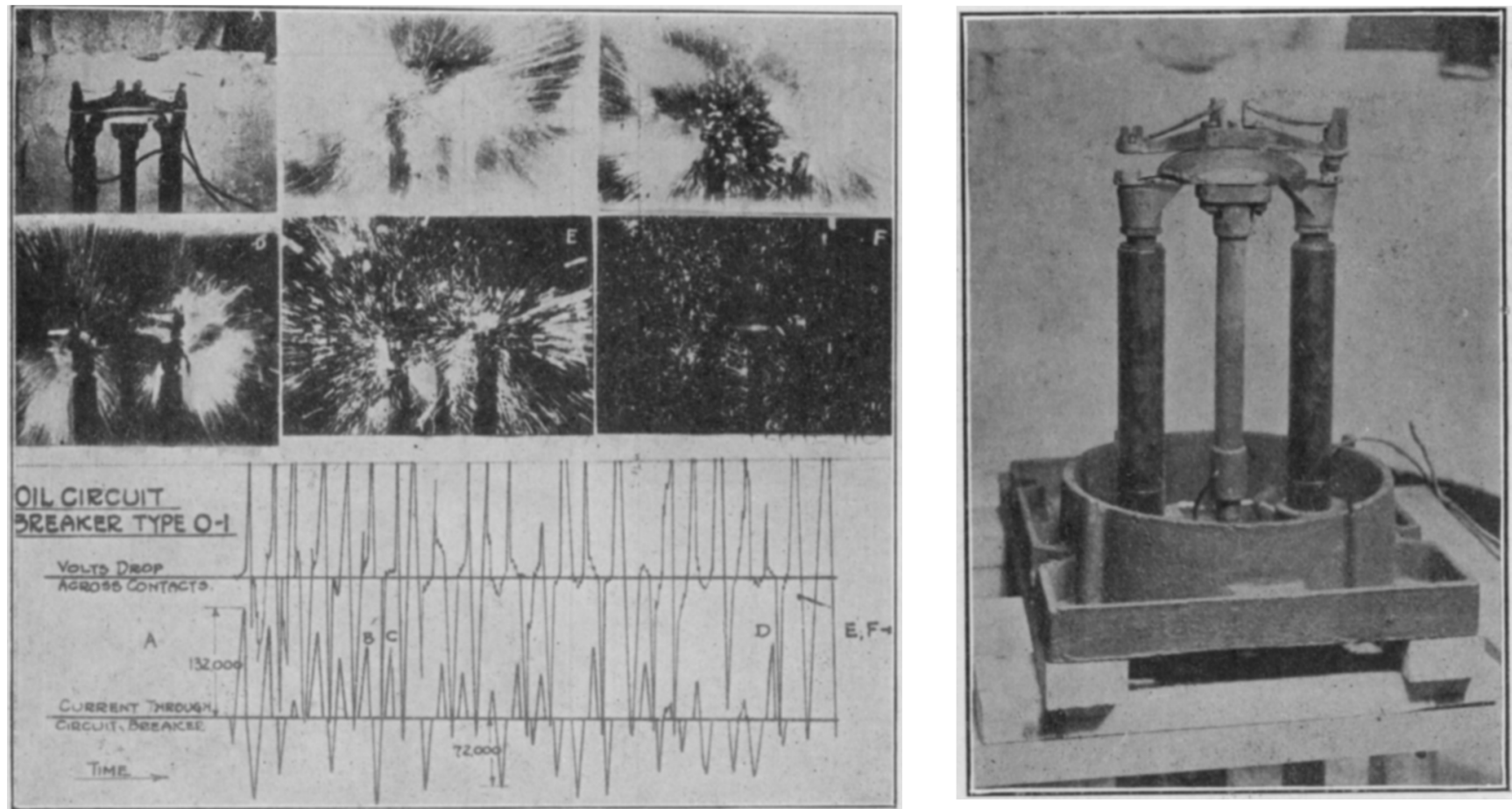

Frg. 13-G. E. Co. H-3 Contact Rods

Standard brass rods tested at 41,000 amperes mean effective, burned off at contact with crossarm in 0.57 sec. Copper rods tested at 91,000 amperes. mean effective, burned off in body of rod in $1.8 \mathrm{sec}$. Copper rod test shown above. Note bending between supports. 

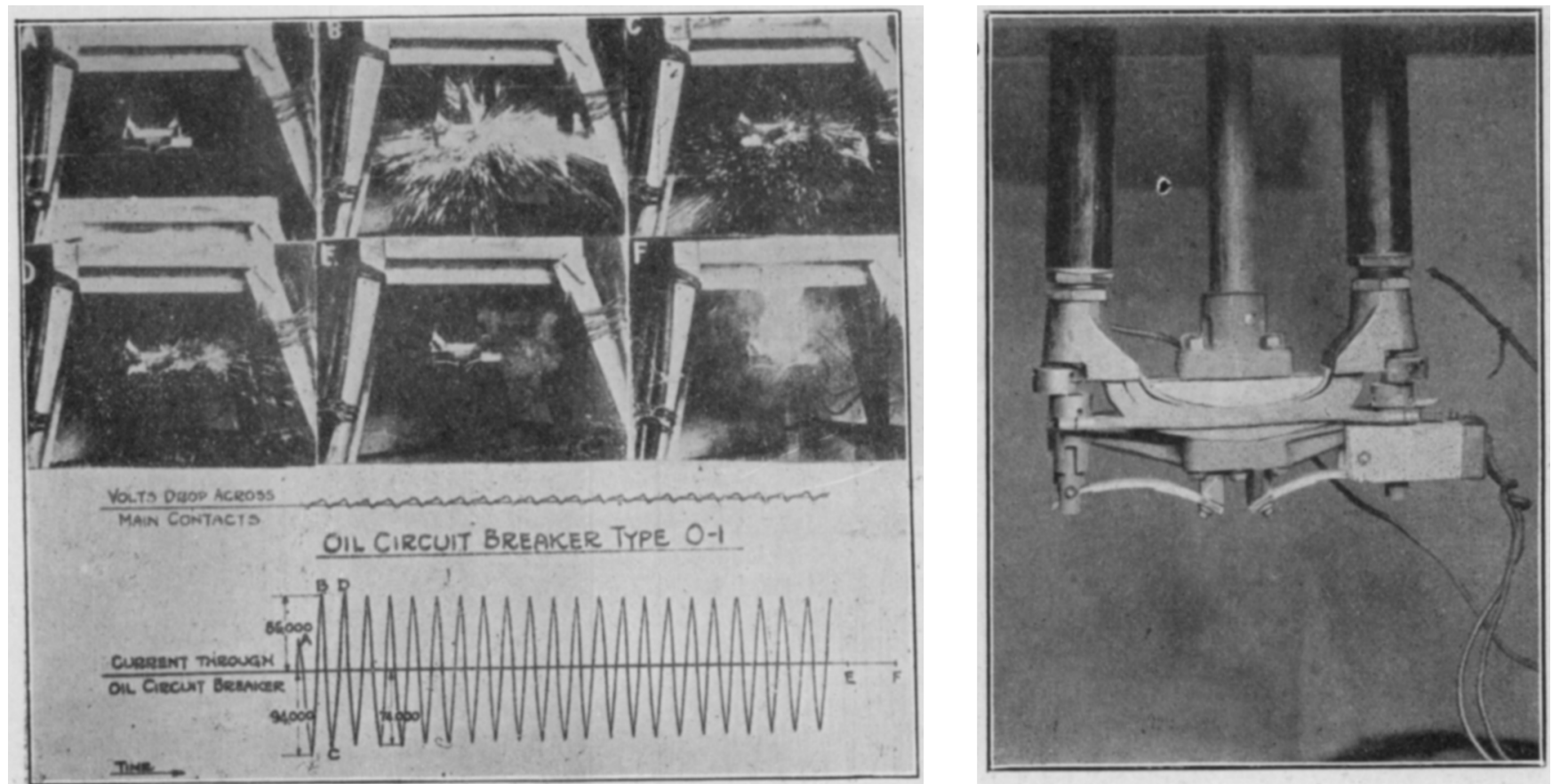

Fig. 14-Westinghouse 0-1 Circuit Breaker

Rating $350,000 \mathrm{kv}-\mathrm{a} ., 88,000$ amperes at 2300 volts.

Tested at 63,000 amperes mean effective. Brushes lifted on flrst $1 / 2$ cycle, froze and remained closed. Total spreading of supports approximately 3/16 in.
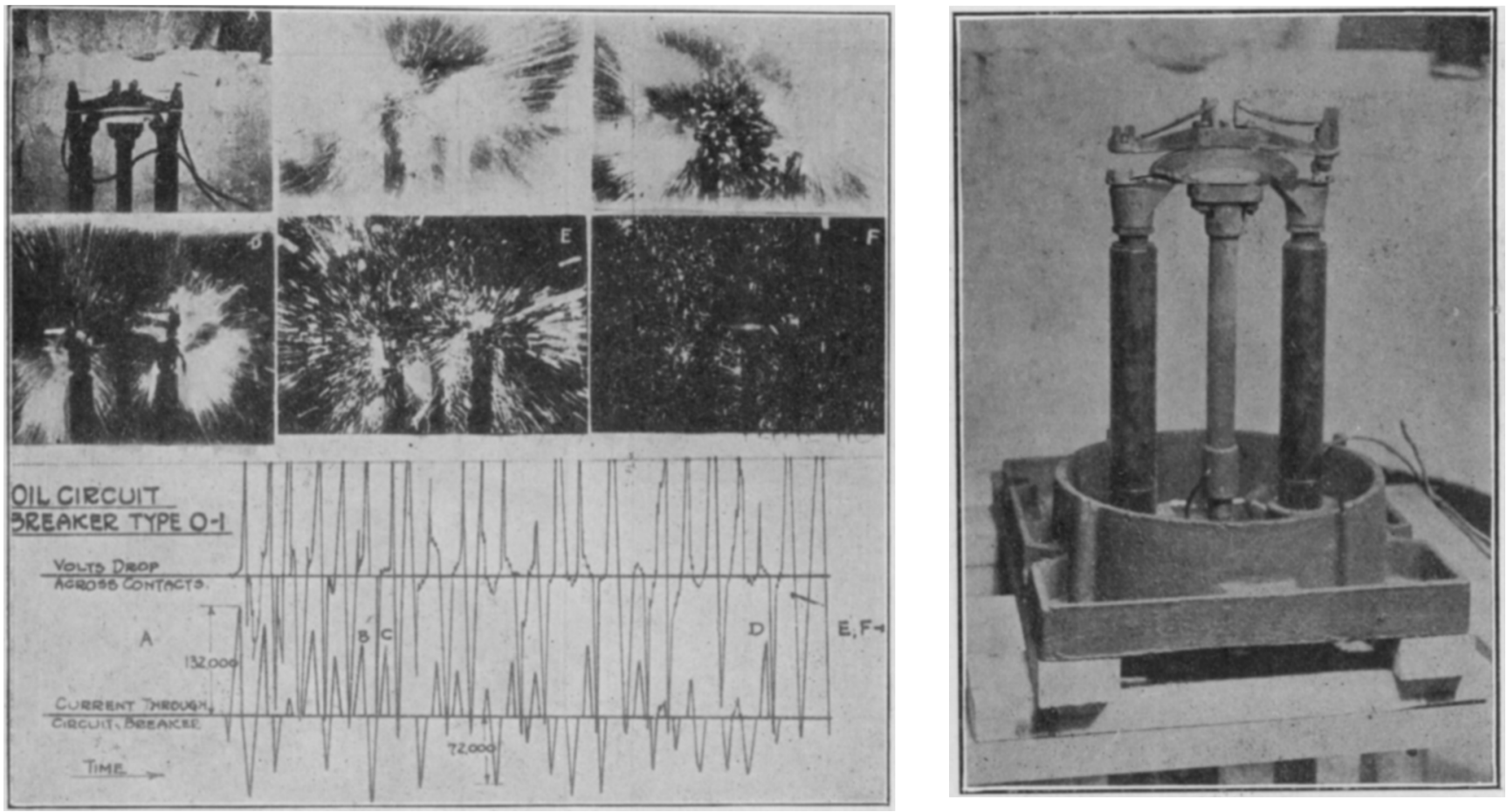

Fig. 15-Westinghouse O-1 Circuit Breaker

Rated at $350,000 \mathrm{kv}-\mathrm{a} ., 88,000$ amperes at 2300 volts.

Tested at 84,000 amperes mean effective. Brushes lifted on first $1 / 2$ cycle and continued intermittently throughout test. Arcing tip destroyed. Considerable spreading of supports during test but no permanent spreading noticed. 

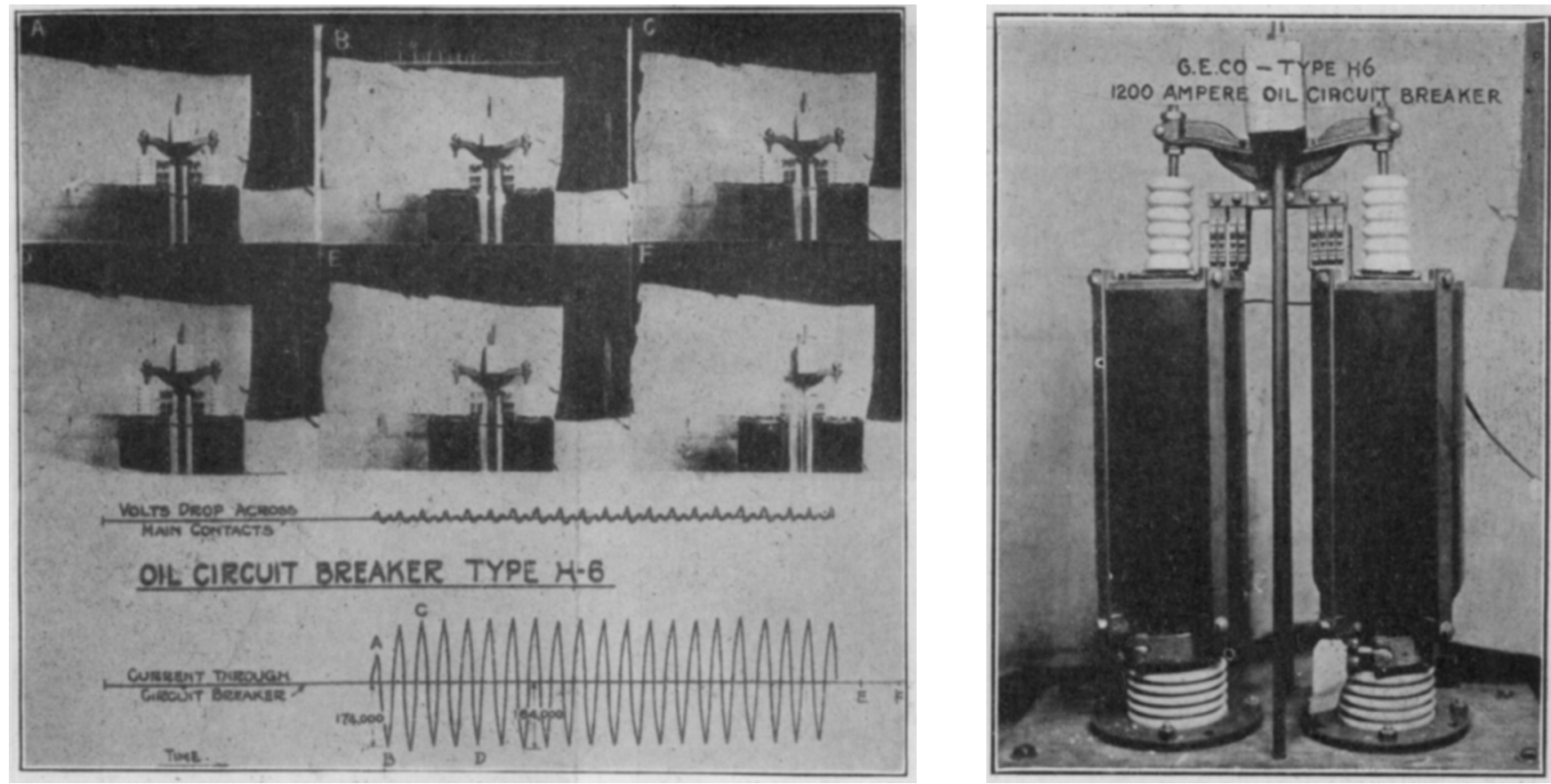

Fig. 16-G. E. Co. H-6 Circuit Breaker

Rated at $350,000 \mathrm{kv}-\mathrm{a} ., 88,000$ amperes at 2300 volts.

Tested at 130,000 amperes mean effective. Pots spread at first $1 / 2$ cycle, no arcing. Parallel paths through moving contact causes attraction of contact fingers and, therefore, tightening instead of opening of contacts. Total spreading of pots approximately one in.
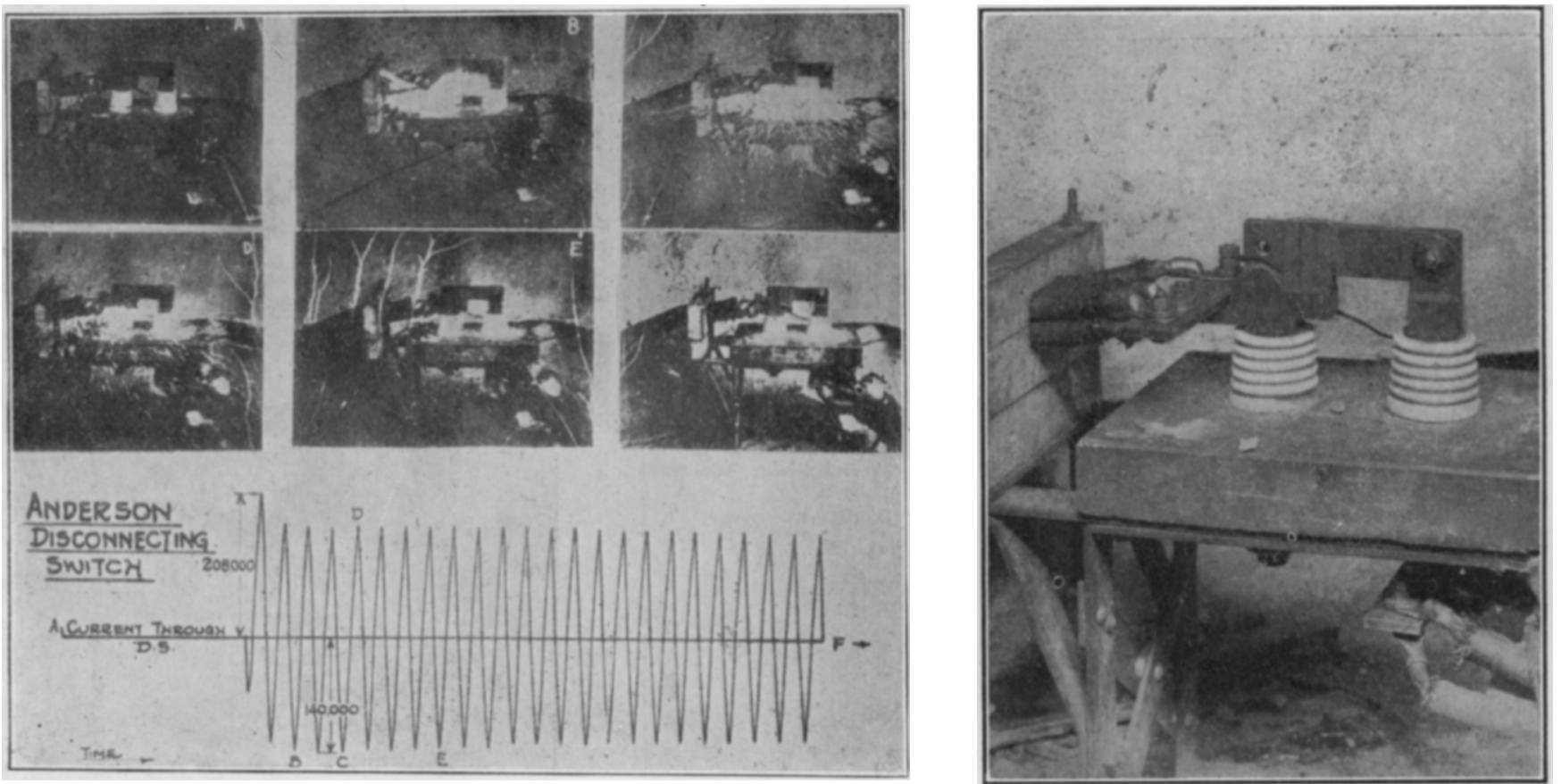

Fig. 17-Anderson Disconnecting Switch With Special Lock

Tested at 130,000 amperes mean effective. Slight chipping of porcelain. No damage to switch. Arcing shown was due to poor contact at terminal. 

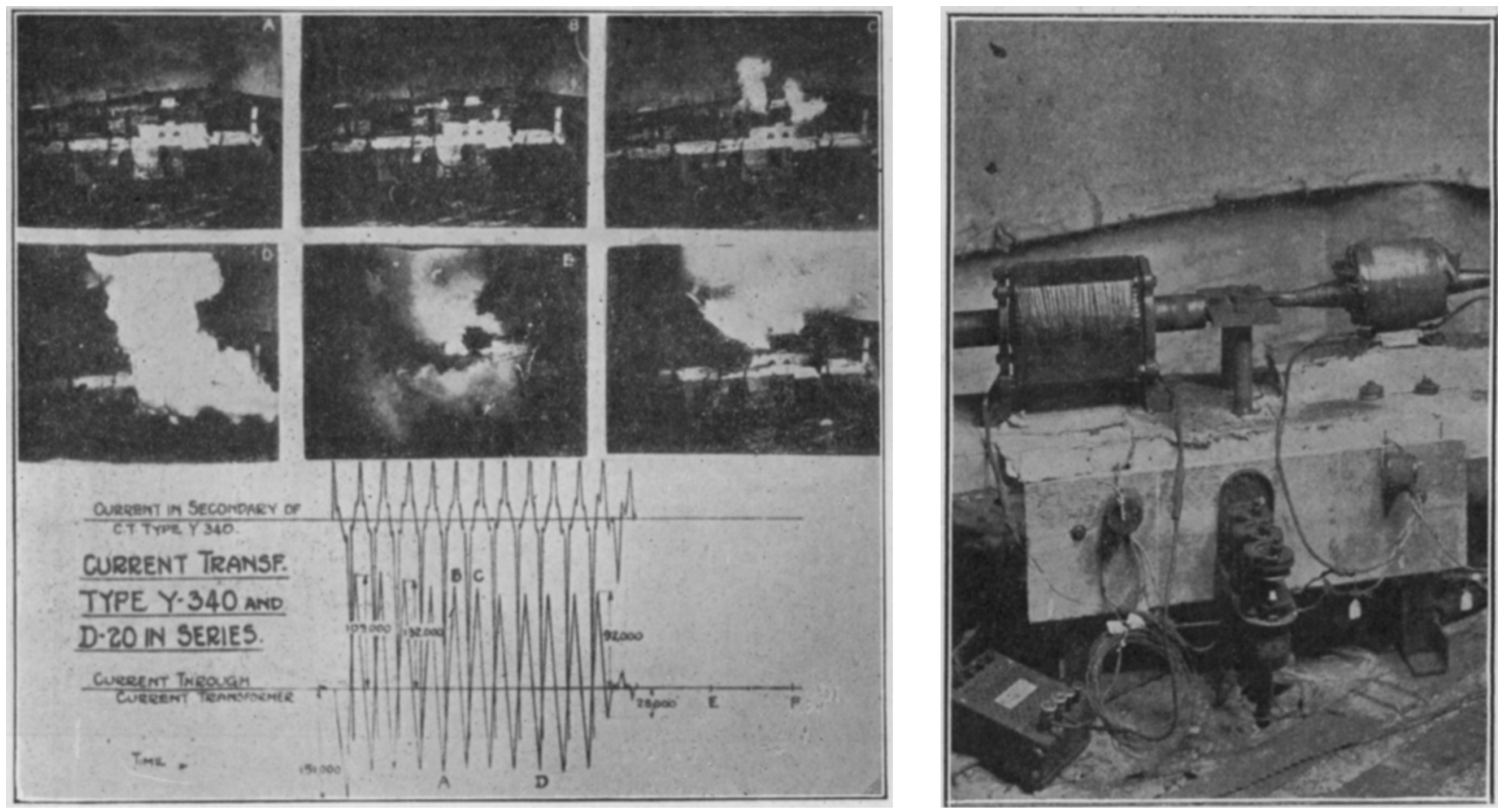

After TEST

Fig. 18-G. E. Co. Current Transformer Y-340 and D-20, Single-Turn.

Tested at 92,000 amperes mean effective. Primary of D-20 blew open after $12 \frac{1}{2}$ cycles. Secondary destroyed. Y-340 not injured. (D-20 is a superseded type).

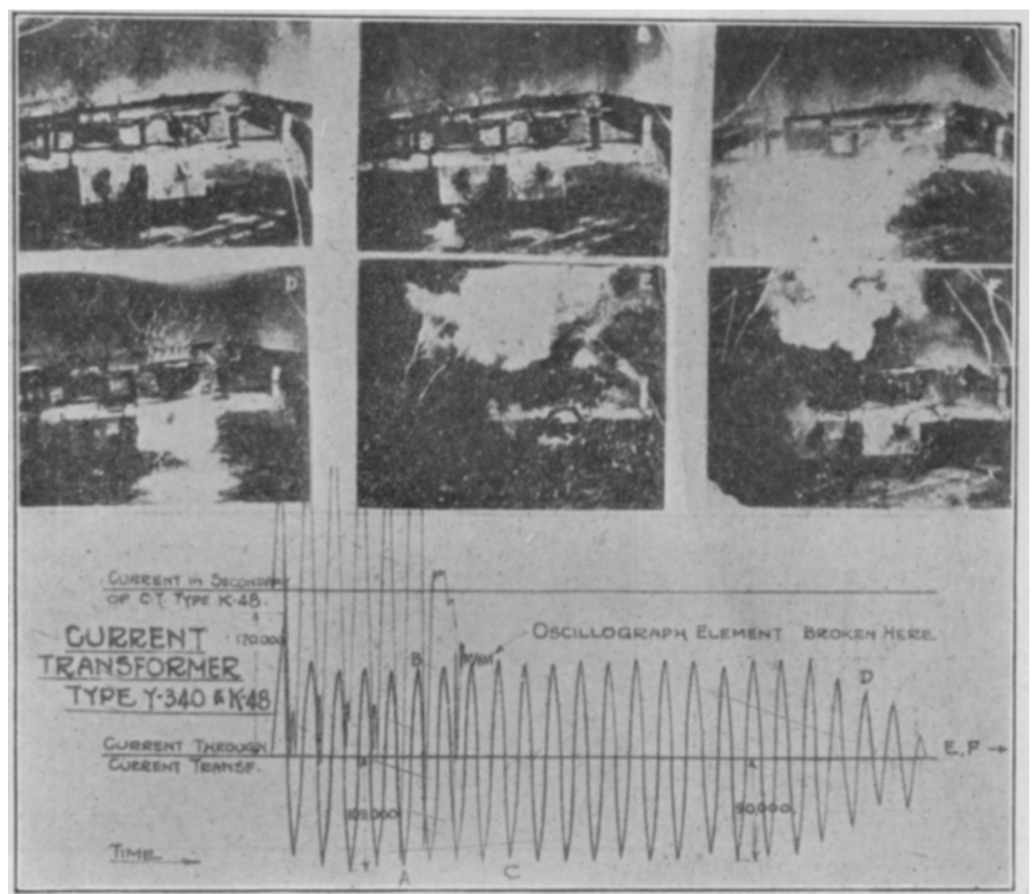

Fig. 19-G. E. Co. Current Trangformers. Y-340 and K-48 Single-Turn.

Tested at 101,000 amperes mean effective. Primary of K-48 opened after $23 \frac{1}{2}$ cycles, due to failure at terminal. Y-340 not injured. 
the mechanical force resulting from the high current. This phenomenon occurs in practise before the operating mechanism has had sufficient time to perform its function in opening under short circuit.

On the basis of the results obtained, the manufacturers have revised the design of their circuit breakers so as to eliminate the trouble due to contact separation and displacements, as shown in Fig. 1 for General Electric Company apparatus, and in Fig. 2 for Westinghouse Company apparatus. Other detail improvements are referred to in the illustrations hereinafter given.

\section{TESTING Equipment}

Current for the tests was supplied by two 10,000-kw. generators in Waterside station, operated in parallel

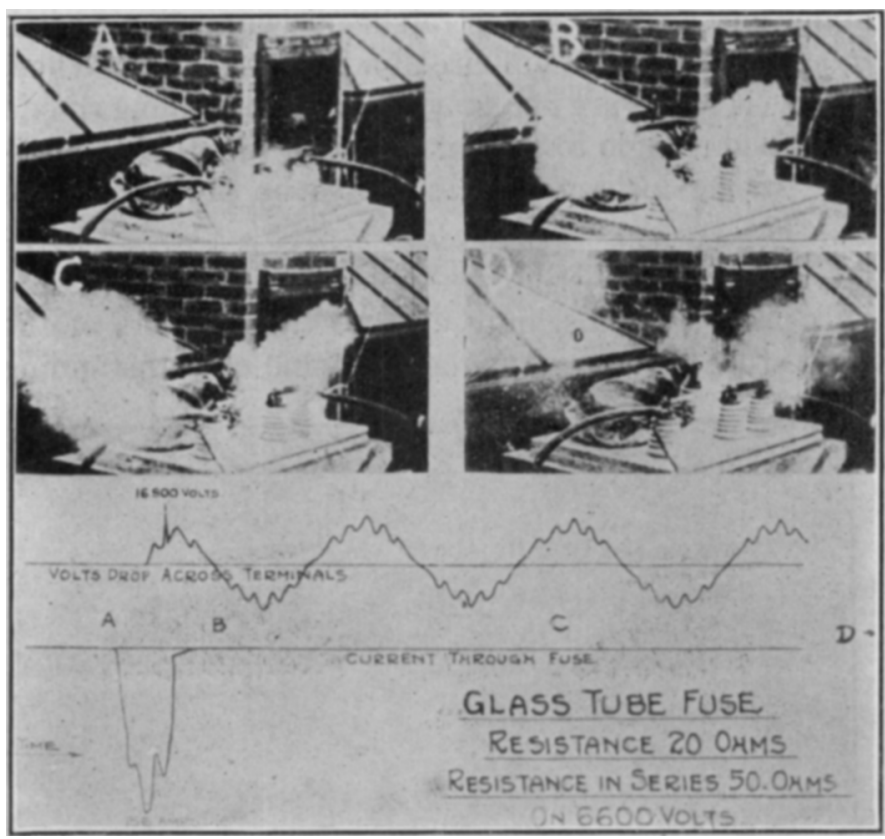

Fig. 20-Glass Tube Fuse of 20 Ohms Resistance With 50 Additional Ohms in Series.

Tested at 6600 volts. Mean effective 156 amperes maximum. Tube was unbroken but asbestos filler was expelled from both ends. Duration of current 0.27 cycle. Circuit opened successfully.

and connected through their reactors to an emergency bus. This bus was connected, through the tie bus reactors, to a second emergency bus to which a 350,000 cir. mil feeder was connected for supplying power for the tests at the West 41st Street substation. (See Fig. 3.)

At the substation, the feeder $H-2$ and the $H-3$ switch of a $3500-\mathrm{kw}$. synchronous converter were connected in series through their $K$ switch and the emergency bus to the high-tension side of a $3850-\mathrm{kv}-\mathrm{a}$., three-phase synchronous converter air-blast transformer. The control circuit of the two $H$ switches was connected to operate from the control switch as a four-break unit. The three high-tension transformer windings were connected in multiple as a single-phase transformer. The six low-tension windings were similarly connected, giving 170 to 200 volts at full voltage.
The records of the test were made by oscillograph, and a motion picture camera was driven synchronously from the feeder supplying energy for the tests; also

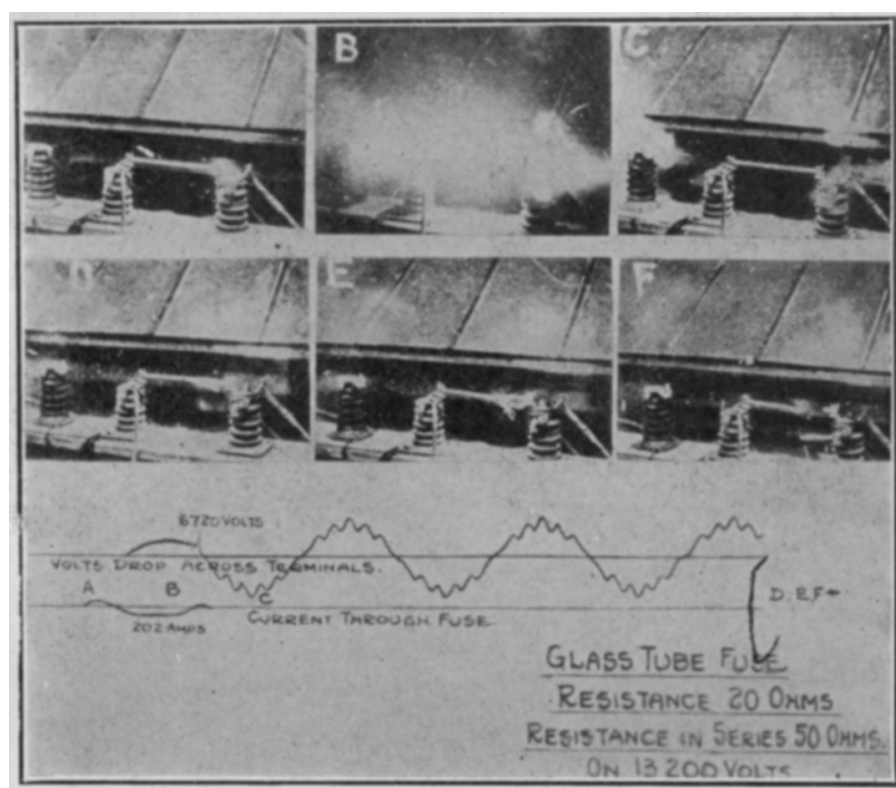

Fig. 21-Glass Tube Fuse of 20 Ohms Resistance With 50 Additional Ohms in Series

Tested at 13,000 volts mean effective, 202 amperes maximum. Fuse exploded. Caps remained in clips. Duration of current 0.58 cycle. Fuse opened circuit.

a Lichtenberg high-speed camera was used. In addition, close-up pictures were made of each subject with the ordinary camera after each test.

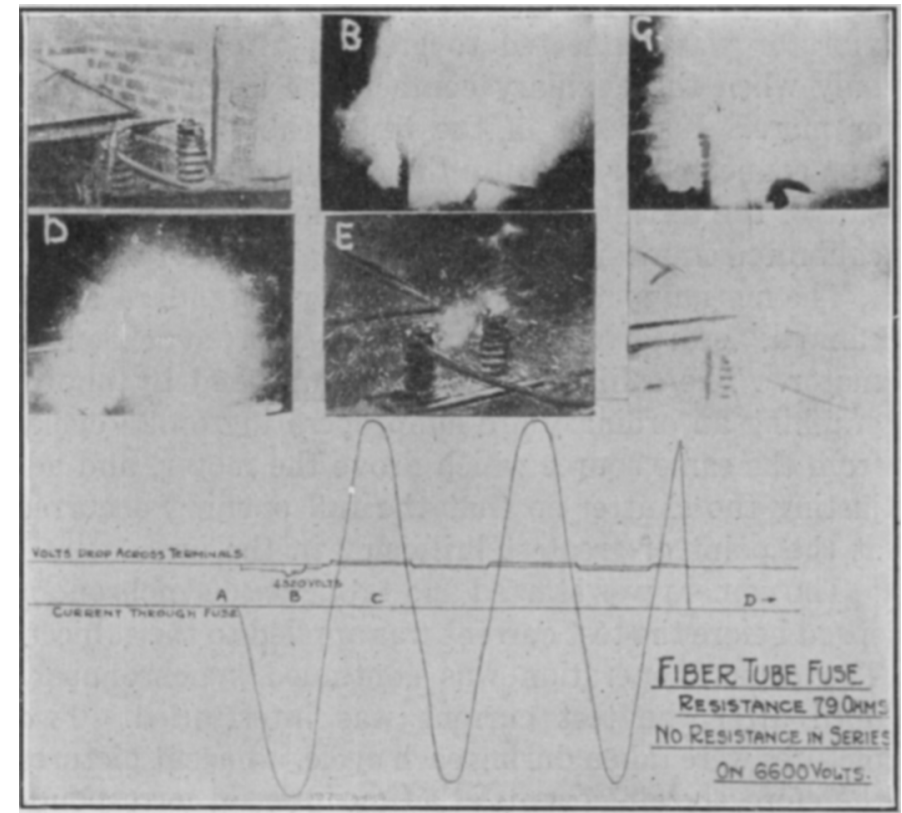

Fig. 22-Fiber Tube Fuse of 79 Ohms Resistance With no Additional Resistance in Series

Tested at 6600 volts mean effective 1970 amperes maximum. Fuse completely blown to pieces. Circuit opened manually. Duration of current 3.1 cycles.

The oscillograph had three vibrators, one of which was used to measure the secondary current in the type E-3 General Electric Company current transformer, 
20,000-ampere, 4000 to 1 ratio. The second vibrator was used to measure the voltage drop across the brush contacts. The third vibrator was used to give a 25 cycle timing wave from the Waterside main bus, ex-

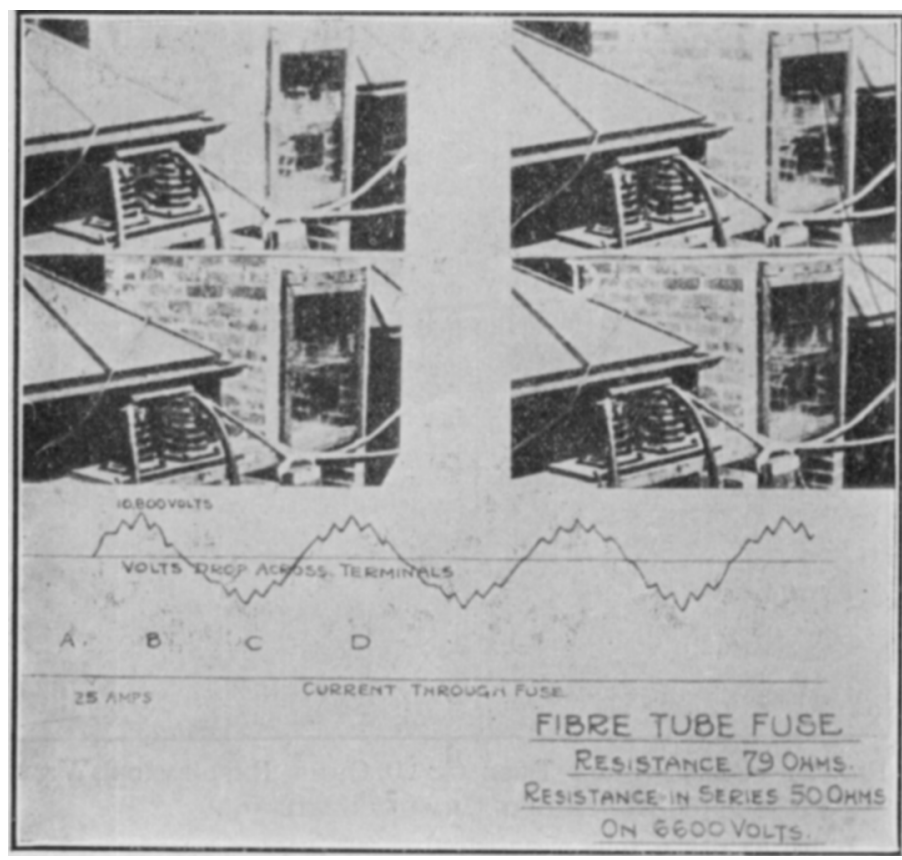

Fig. 23-Fiber Tube Fuse of 79 Ohms Resistance With 50 Ohms Additional in Series

Tested at 6600 volts mean effective, 25 amperes maximum. Fuse opened the circuit without visible disturbance. Duration of current 0.02 cycle.

cepting in tests of circuit breakers having auxiliary arcing tips. On circuit breakers so equipped the third vibrator was connected to give an alternating wave only when the auxiliary contact was lifted $1 / 32$ inch or more. For some of the tests, the third vibrator was connected to measure the current on the primary side of the testing transformer. The oscillograph was calibrated immediately before and after the tests.

The motion pictures were made by a standard Moye camera, gear-driven, from a $1 / 2$-h. p. synchronous motor. The calibration was accomplished by photographing an ordinary arc lamp operating on 25 cycles from the same source which drove the motor, and adjusting the shutter so that the full opening occurred at the point of greatest brilliancy in the arc.

The camera was started and brought to synchronous speed before the test current was applied to the subject. The camera operation was continued synchronously until after the test current was interrupted. Two pictures were taken during each cycle, adjacent pictures therefore, showing events at a time interval corresponding to 180 electrical degrees, or one-fiftieth of one second. The camera shutter design was such that the exposure' for each picture lasted during about 60 electrical degrees. Figs. 4 and 5 show the apparatus.

The Lichtenberg camera was equipped with a lens board and 24 lenses arranged to give successive exposures. It was set to take its 24 pictures during the first two cycles of the test current. As the tests pro- gressed, however, the time of exposure was increased somewhat to obtain better negatives. Although these pictures were, in general, a success, they are not shown herein, as the motion pictures, being in synchronism with the oscillograph records, more adequately illustrate the results obtained.

\section{Results of Tests}

From all the records, in Figs. 6 to 16 inclusive, are combined characteristic results of motion pictures and oscillographs for the apparatus tested.

\section{DisconneCTING Switches}

The same mechanical stresses caused by flow of high currents, as reviewed in the paragraph on oil circuit breakers, apply, to a large extent, to the design of disconnecting switches. The ideal installation would be a straight disconnecting switch in series with the main circuit without bends. When, however, bends are necessary, the blade opening should be at right angle to the main lead. In addition, suitable strong locking devices are to be provided. See Fig. 17.

\section{CURRENT TRANSFORMERS}

In large systems, only current transformers of the single-turn, primary type are capable of withstanding

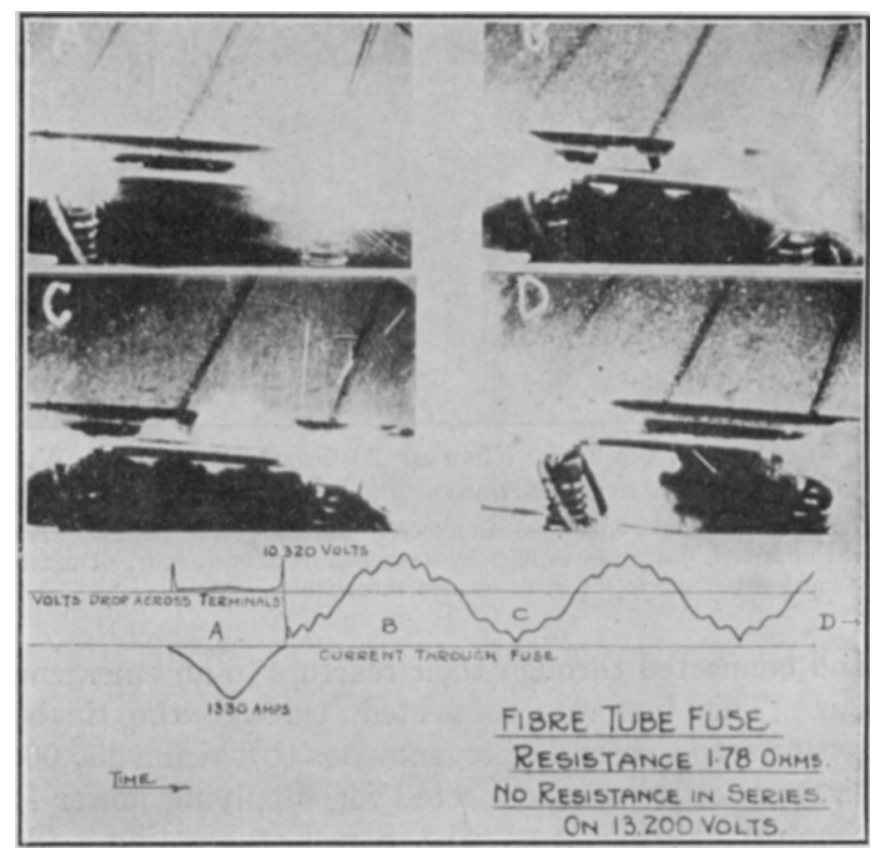

Fig. 24-Fiber Tube Fuse of 1.78 Ohms Resistance With no Additional Resistance in Series

Tested at 13,000 volts mean effective, 1330 amperes maximum. Fuse blew out end of caps but opened the circuit. Duration of current 0.54 cycle.

short circuits as may occur on the system. The other current transformers are too weak, and will be either ruptured mechanically or destroyed thermally. See Figs. 18 and 19.

\section{Potential Transformer Fuses}

Extensive tests were made with and without resistance in series. The tests have conclusively proved 
that no type of potential fuse on the market can satisfactorily open the circuit without a resistance in series. The company first used a resistance wire wound spirally on a rope core and insulated suitably for the voltage on which it was applied.
Recently, the suggestion has been made to use an asbestos card with a resistance wire wound on it in series with the fuse. Where space does not permit the use of the high-resistance lead, this substitute may be of advantage. See Figs. 20 to 24, inclusive.

\title{
The Maximum Safe Operating Temperature of Low-Voltage Paper-Insulated Cables
}

\author{
BY W. A. DEL MAR \\ Chief Engineer, Habirshaw Electric Cable Co.
}

\begin{abstract}
The Standards of the Institute state that for low-voltage cables the maximum safe operating temperature is 85 deg. cent. Experiments show that continuous operation at 100 deg. cent. for less than a month, seriously impairs the mechanical condition of impregnated paper. A standard of permissible mechanical condition should, therefore, be established, if such high temperatures are to be allowed. Operation at higher temperatures than allowed by the present Standards is, however, in the nature of a gamble and it is questionable whether the Standards should take cognizance of it.
\end{abstract}

\section{Statement of the Problem}

N OTHING would seem more simple than to determine the maximum safe operating temperature of an insulating material such as impregnated paper; but the problem is really very complicated as several preliminary problems of an important character must be settled before the main problem can be adequately attacked. These preliminary problems are as follows:

1. What is the criterion of quality of paper insulation by which we may say whether it is satisfactory for service?

2. What is the effect of the continued application of various degrees of heat, expressed in terms of the criterion selected?

3. Will intermittent heat have the same effect as continuous heat provided the aggregate time of exposure and the temperature are the same in both cases?

4. If the above questions should be satisfactorily answered, what form of rule should be adopted so as to make the best economic use of the information thus obtained?

5. If a rational rule for the maximum permissible temperature of paper insulation should be developed, how can the hottest-spot temperature of a cable in a duct be measured in order to ensure that the cable is working within the rule?

These questions cannot all be answered at the present time, and the object of this group of papers is to gather together such data as are available in order that the Standards Committee of the Institute may be able to revise its present rule for the temperature limits of paper insulation in the light of the best information which the members of the Institute can furnish.

To be presented at the 9 th Midwinter Convention of the A.I. E. E. February 16-18, 1921.

\section{CRITERION OF QUALITY}

In the case of low-voltage cables, which are the only ones under present consideration, the criterion of quality by which we may judge whether the cable is usable, should be the mechanical strength, because it is that quality which determines whether the cable can withstand handling, expansion and contraction, and possible reinstallation. New cables of the best quality have but little margin of strength to take care of the stresses imposed on the insulation during installation. Large cables are often installed in splicing chambers originally designed for small cables, and are consequently bent on curves of dangerously small radius, and are subjected to very rough handling. Even where splicing chambers are adequately designed, the cablesare often handled with entire disregard of their mechanical limitations. However, once the cables are installed, they are free from mechanical stresses except such as may result from expansion and contraction due to variations of temperature. A different criterion of quality may therefore conceivably be adopted for cables after they are installed from that for new cables, but the use of such a standard would preclude the possibility of reinstalling cables which have deteriorated to that standard.

Some cable specifications contain clauses requiring the paper to have a certain minimum tensile strength, but tensile strength tests are unsatisfactory because the paper may become brittle, and may tear easily, while the tensile strength remains quite high.

Bursting strength tests, as made on a Mullen tester, are unsatisfactory for the same reason. A test, which proved to be really satisfactory, is the tearing test. A piece of paper about three centimeters wide is carefully cut with a razor along its center line from one end to about its center, and a pencil mark made one centimeter beyond, as shown in Fig. 1. It is then suspended 